\title{
SANNE TAEKEMA*
}

\section{METHODOLOGIES OF RULE OF LAW RESEARCH: WHY LE- GAL PHILOSOPHY NEEDS EMPIRICAL AND DOCTRINAL SCHOLARSHIP}

(Accepted 27 April 2020)

\begin{abstract}
Rule of law is a concept that is regularly debated by legal philosophers, often in connection to discussion of the concept of law. In this article, the focus is not on the substance of the conceptual claims, but on the methodologies employed by legal philosophers, investigating seminal articles on the rule of law by Joseph Raz and Jeremy Waldron. I argue that their philosophical argumentations often crucially depend on empirical or legal doctrinal arguments. However, these arguments remain underdeveloped. I explore how these arguments could be linked to approaches related to rule of law in different fields of legal scholarship and investigate how the methodologies of these fields may complement each other. Thus, the article aims to provide an argument for a specific form of triangulation of three kinds of approaches to the rule of law: philosophical, socialscientific and legal doctrinal. This method of triangulation is illustrated by a discussion of the World Justice Project's Rule of Law Index.
\end{abstract}

\section{INTRODUCTION}

The rule of law is one of legal philosophy's favourites. It is a concept that is closely linked to the general questions of the concept of law, to the debate on descriptive versus normative accounts of law, and to other central concepts of legal philosophy, such as rules and authority. However, the rule of law is not simply a hobbyhorse for legal philosophers; it plays a central role in the practice of law as a normative idea, which legal systems around the world should uphold. What the rule of law consists of is therefore also of significant practical importance. The starting point for my argument here is that the importance of the rule of law idea also has methodological consequences: It requires attention to the way the rule of law 
functions and is perceived. Thus, this article raises the following questions: How do empirical and legal arguments figure in legal philosophers' accounts of the rule of law, and how can the use of these arguments be improved?

My basic argument in this article is that the turn to empirical and legal arguments by legal philosophers makes it useful to engage empirical social science and doctrinal legal scholarship in order to support those arguments. Rather than simply positing an empirical claim about people or society or a claim about the character of legal institutions or procedures, and making the conceptual normative argument dependent on these, legal philosophers could benefit from considering the results of social-scientific work and legal scholarship on the rule of law. More tentatively, I advance a characterization of the distinctive approach of each field of rule-of-law scholarship and investigate how these methodological stances enable the complementarity of the three perspectives. In addition to providing additional support for necessary empirical or legal claims in the conceptual argument, these other disciplinary approaches also challenge legal philosophers to ask different questions. These questions need to be taken more seriously than they are now.

As a starting point, I present the theories of Joseph Raz and Jeremy Waldron as two good examples of conceptual arguments about the character and principles of the rule of law. In this article, I am not concerned with the debates as such among legal philosophers about the character of the rule of law and its central values, or about the relationship between the rule of law and theories about the concept of law. Raz and Waldron both defend their own plausible conceptions of the rule of law, which I accept as viable theories of the rule of law. I focus on their arguments for the content of the rule of law: Waldron's claim that the rule of law is not primarily formal or substantive but procedural, and Raz's exposition of the eight principles that make up the rule of law. I will show at which points and in what manner they turn to empirical or legal claims (Section II). I then proceed by examining how those particular claims could be further supported by work in other disciplines. Waldron's claim leads to a discussion of socio-legal work on legal consciousness in Section III and, together with Raz's claims, to a discussion of legal scholarship on the institutions of the rule of law in Section IV. In 
both discussions, the positive supportive claims are contrasted with critical comments that could be made of the conceptual philosophical work. In Section V, I present my own proposal of triangulation of disciplines and discuss how the distinctive methodological approaches can complement each other. In Section VI, I apply the triangulation of legal philosophy, socio-legal studies and doctrinal scholarship to the example of the Rule of Law Index.

One cautionary note regarding legal philosophy needs to be made beforehand. In this article, I do not distinguish the project of analytical and descriptive legal philosophy from normative and evaluative legal philosophy. ${ }^{1}$ Although analytical philosophy in the tradition of H.L.A. Hart is more clearly concerned with conceptual argument, a very similar orientation on concepts is characteristic of the more normative philosophers such as Ronald Dworkin, John Finnis or Jeremy Waldron. Most importantly, in the context of this article, they are in conversation with each other about the rule of law, mostly relying on conceptual argument about normative concepts related to the rule of law and supporting conceptual claims with normative argument. Although in other debates, such as the debate on the nature of law, the distinction between analytical and normative positions is a crucial one to make, in this debate on the rule of law it is possible to treat them as part of the same set of legal philosophies.

\section{CONCEPTUAL THEORIES ON THE RULE OF LAW: RAZ AND WALDRON}

Most legal philosophers would agree with the statement by Joseph $\mathrm{Raz}$ that the rule of law is a political ideal. It is political in the sense that it governs political decision-making and the design of rules, and it is an ideal because it is a valuable idea in need of realization. Legal philosophers see it as their task to clarify the normative concept of the rule of law, and often also to provide a justification of the rule of law's importance. There is a quibble about the right order in which to do this: should we first explain what normative components the rule of law has and which principles satisfy it or should we first

\footnotetext{
${ }^{1}$ The debate on the methodology of legal theory is well described by Julie Dickson, Evaluation and Legal Theory (Oxford: Hart 2001); Julie Dickson, 'Methodology in Jurisprudence: A Critical Survey, Legal Theory 10 (2004), 117-156; and Michael Giudice, Understanding the Nature of Law: A Case for Constructive Conceptual Explanation, (Cheltenham: Edward Elgar 2015).
} 
consider what the rule of law is for? This is the debate about the 'laundry lists' of the rule of law versus the teleological approach proposed by Martin Krygier. ${ }^{2}$ Of course, it matters what other values the rule of law is argued to promote because this is bound to influence the conception of the rule of law or the principles that support it. However, none of the theories of the rule of law can avoid giving substance to their conception - what does content of the rule of law amount to? - and arguing why that conception is the right one.

Here I will discuss two of those conceptions of the rule of law and the arguments for them: the conceptions offered by Joseph Raz and by Jeremy Waldron. ${ }^{3}$ A classic in the rule-of-law literature, 'The Rule of Law and its Virtue' by Raz is most often read in the context of the debate between Hart and Fuller on the rule-of-law principles as an internal morality of law. ${ }^{4}$ However, a significant part of the text is devoted to an exposition of the principles that Raz sees as the core of the rule of law as a valuable political ideal. ${ }^{5}$ Raz presents his eight principles of the rule of law as following from the basic intuition that 'the law must be capable of guiding its subjects'. ${ }^{6}$ The first two principles, that '[a]ll laws should be prospective, open, and clear' and '[1] aws should be relatively stable', Raz derives from his basic intuition of guidance. ${ }^{7}$ A retroactive law cannot guide people, because there is nothing to be guided by at the moment of action. The same can be argued for obscure or ambiguous laws or constantly changing ones. It is striking, of course, that Raz (usually pitted against Fuller in jurisprudential debates) has a very similar argument to that of Fuller in The Morality of Law: failure to observe these principles makes the law incapable of governing conduct, and conformity to these principles is a matter of degree. Raz adds a third principle: that the

\footnotetext{
${ }^{2}$ Martin Krygier, 'The Rule of Law: Legality, Teleology, Sociology'. In G. Palombella G and N. Walker (eds.) Re-locating the Rule of Law (Oxford: Hart 2009), pp. 45-70; Martin Krygier, 'Four Puzzles about the Rule of Law: Why, What, Where? And Who Cares?' In: J. Fleming (ed.) Getting to the Rule of Law (New York: New York University Press 2011), pp. 64-104.

${ }^{3}$ The discussion will be focused on their seminal articles on the rule of law, rather than on their work more broadly.

${ }^{4}$ Joseph Raz, 'The Rule of Law and its Virtue', in The Authority of Law: Essays on Law and Morality (Oxford: Clarendon, 1979), pp. 210-229; see Kristen Rundle, 'Form and agency in Raz's legal positivism', Law and Philosophy 32 (2013), 767-791.

${ }^{5}$ Mark J. Bennett, 'Hart and Raz on the non-instrumental moral value of the rule of law: A reconsideration', Law and Philosophy 30 (2011), 603-635 at p. 626.

${ }^{6}$ Joseph Raz, Authority of Law, p. 213.

${ }^{7}$ Raz, Authority of Law, p. 214.
} 
making of particular legal orders needs to be guided by general rules conforming to the first two principles. All of this is a conceptual argument based on the guidance function of law. However, the rest of the principles Raz enumerates no longer directly follow from the basic intuition. Principles four to seven all concern the place and functioning of the judiciary in a legal system: its independence, the importance of principles of natural justice, the power to review ruleof-law conformity and access to the courts. The eighth principle is rather specific, on limitation of the powers of crime-preventing agencies, which I will not discuss further. I am interested in the list of court-related principles. Where do these come from? Can law only guide its subjects if there are independent courts, which are easily accessible? How do these principles follow from the conceptual claim about the character of law? Raz does give an argument for the independence of the judiciary linking it to guidance, but with a twist:

(4) The independence of the judiciary must be guaranteed. It is of the essence of municipal legal systems that they institute judicial bodies charged, among other things, with the duty of applying the law to cases brought before them and whose judgments and conclusions as to the legal merits of those cases are final. Since just about any matter arising under any law can be subject to a conclusive court judgment, it is obvious that it is futile to base one's action on the law if when the matter comes to adjudication the courts will not apply the law and will act for some other reasons. ${ }^{8}$

At first sight a guidance argument is made here: 'just about any' legal question can be subject to a court judgment, so you need to know what these judgments are in order to know what the law asks of you. This argument, however, needs a few extra steps. Unlike Hart, who gives an extensive argument for the need for rules of adjudication in legal systems, Raz only posits that it is essential to have courts. A further argument is needed to show why general rules combined with particular orders are not enough. This could be done on the basis of Hart's work. ${ }^{9}$

More crucially, the independence of the judiciary does not really follow from this reasoning. It is the duty of judges to apply the law in order to provide guidance, because people need to know what the law is, and things become complicated if judges do not apply the legal rules. But what does this have to do with independent decisions by judges? Why might it not be an administrative official, subordinate to the government, who applies the rules? The guidance

\footnotetext{
${ }^{8}$ Raz, Authority of Law, pp. 216-217.

${ }^{9}$ H.L.A. Hart, The Concept of Law, $2^{\text {nd }}$ ed. (Oxford: Clarendon, 1994), pp. 91-99.
} 
function of law does not generate a conceptual argument that requires independence. It seems much more likely that Raz uses the character of existing legal systems that he knows about to come up with this principle. Supporting arguments for principles five to seven are even less informative. For example, Raz states that the principles of natural justice include 'open and fair hearing, absence of bias, and the like' and to be 'obviously essential for the correct application of the law. ${ }^{10}$ Are these principles essential to get at the facts of court cases or for interpretation of the laws? What else is essential other than a fair hearing and impartiality? It also matters whose guidance is meant: Is it the citizen who is involved in the case? That would be strange, because court cases are backward-looking: They consider whether the law has been applied correctly. If it is guidance for the broader citizenry, it seems that the principles of natural justice are not so important. To them, the outcome of the case matters. Principles of natural justice are important for citizens as a guarantee of the fairness of procedures they may be involved in, but that is not a matter of guidance.

There are fine arguments for these principles of judicial independence, impartiality, etc., but they are not conceptual; they refer to actual legal systems and the experiences within these systems. The four principles concerning the judiciary make sense, once we place them in the context of legal doctrinal arguments about the structure and functioning of legal systems. Before I go into the nature of those arguments in Section IV, I turn to Waldron's procedural rule of law.

In 'The Concept and the Rule of Law', and a number of related articles, ${ }^{11}$ Jeremy Waldron takes issue with the standard division of rule-of-law theories into the categories of formal and substantive theories. ${ }^{12}$ Formal theories require only form-related characteristics of legal rules such as clarity and prospectivity, while substantive theories also require certain content, such as non-discrimination or protection of individual rights. Waldron disagrees with this catego-

\footnotetext{
${ }^{10} \mathrm{Raz}$, Authority of Law, p. 217.

${ }^{11}$ Jeremy Waldron, 'The Concept and the Rule of Law', Georgia Law Review 43 (2008), 1-61; Jeremy Waldron, 'The Rule of Law and the Importance of Procedure', In J. Fleming (ed.) Getting to the Rule of Law (New York/London: New York University Press 2011), pp. 3-31; Jeremy Waldron, 'Is the Rule of Law an Essentially Contested Concept (in Florida)?', Law and Philosophy 21 (2002), 137-164.

${ }^{12}$ Paul P. Craig, 'Formal and substantive conceptions of the rule of law: an analytical framework'. Public Law (1997), 467-487; Brian Z. Tamanaha, On the Rule of Law. History, Politics, Theory (Cambridge: Cambridge University Press, 2004), pp. 91-113.
} 
rization because he believes a crucial strand of rule-of-law theorizing does not receive adequate recognition in either the formal or the substantive view. He argues that the prime value of the rule of law is procedural: It is the access to courts and the procedures within them. To some extent, the procedural rule of law is complementary to the formal aspects; the eight principles of Raz are partly formal and partly procedural. However, Waldron argues, there are situations in which demands of procedural rule of law are in tension with formal requirements. ${ }^{13}$ Procedural rule of law demands that citizens have a voice in court procedures, but this entails that their arguments are listened to and may be used to interpret legal rules in novel ways, which makes law less predictable, therefore detracting from a central formal requirement.

What I am interested in here are Waldron's arguments for highlighting procedure in the rule of law. His starting point is a comparison between a philosophical and a popular idea of the rule of law. He acknowledges that in legal philosophy the rule of law is primarily thought of as formal (e.g., by Raz and Fuller), but he claims that in popular opinion the rule of law is seen as procedural:

\footnotetext{
When people say, for example, that the Rule of Law is threatened on the streets of Islamabad or in the cages at Guantanamo, it is the procedural elements they have in mind, much more than the traditional virtues of clarity, prospectivity, determinacy, and knowing where you stand. They are worried about the independence of the Pakistani courts and about the due process rights of detainees in the war on terror. ${ }^{14}$
}

Waldron thus claims that in the eyes of ordinary people rather than theorists, the formal elements of the rule of law are subordinate to procedural elements, which include the independence of courts and procedural rights.

His reasoning for the importance of procedure is further supported by a conceptual argument that, like the rule of law, the concept of law too is more court-centred than most theorists acknowledge. Of the five essential requirements for counting as a legal system, this is the first he discusses: 'First and foremost, I do not think we should regard something as a legal system absent the existence and operation of the sort of institutions we call courts'. ${ }^{15}$ Waldron offers this as a suggestion, and does not provide further arguments other than, again, what people ordinarily think. 'Most

\footnotetext{
${ }^{13}$ Waldron, 'The Rule of Law and the Importance of Procedure', p. 19.

${ }^{14}$ Waldron, 'The Concept and the Rule of Law', p. 9.

${ }^{15}$ Waldron, 'The Concept and the Rule of Law', p. 20.
} 
people, I think, would regard hearings and impartial proceedings and the accompanying safeguards - as an essential rather than a contingent feature of the institutional arrangements we call legal systems' ${ }^{16}$ Waldron has much to say about the further moral reasons to value the procedural element in law and the rule of law, but here I want to draw attention to his strategy of countering the conceptual accounts of legal philosophers by appealing to how the term is ordinarily used' and what ordinary people 'have in mind'. ${ }^{17}$

To summarize the point of this section, it is useful to give a brief characterization of how I understand conceptual argument as practiced by legal philosophers. Conceptual argument is the explanation or justification of the meaning of central concepts of law, such as rule of law, in terms of other concepts in a theoretical argumentation. Such argumentation often builds on basic intuitions, such as Raz's notion of the guidance function of law. It may also use the common-sense meaning of a concept as a building block in a conceptual account, but on its own this is not sufficient. ${ }^{18} \mathrm{~A}$ good conceptual argument gives a coherent explanation or justification of the central concepts and thus goes beyond direct appeal to the ordinary understanding of a term.

Because Waldron so explicitly contrasts philosophers' arguments with what ordinary people think, I interpret Waldron's appeals to what people say and think as empirical claims: how people in fact, in political and popular debate, understand the rule of law. However, it is questionable whether we can rely on common sense and our own understandings of popular debate as an adequate source of such understanding. In the next two sections, I will argue that a turn to empirical social science and to doctrinal legal scholarship is helpful to support, and in some respects criticize or question, the non-conceptual arguments made in legal-theoretical accounts of the rule of law.

\footnotetext{
${ }^{16}$ Waldron, 'The Concept and the Rule of Law', p. 22.

${ }^{17}$ Waldron, 'The Concept and the Rule of Law', p. 22 and p. 9 respectively.

${ }^{18}$ See Alex Langlinais and Brian Leiter, 'The Methodology of Legal Philosophy', in: H. Cappelen, T.S. Gendler, \& J. Hawthorne (eds.), The Oxford Handbook of Philosophical Methodology (Oxford: Oxford University Press 2016), DOI: 10.1093/oxfordhb/9780199668779.013.9, who give a useful exposition of Hart's linguistic or conceptual analysis, also discussing how it differs from ordinary language philosophy.
} 


\section{MAKING USE OF EMPIRICAL SOCIAL SCIENCE}

The starting point here is where I left the discussion of Waldron: the claim that people have in mind independence and due process when they think of the value of the rule of law. This is an empirical claim about the actual ideas ordinary people have about the rule of law, for which Waldron only advances support by way of media reports. Does the fact that people criticized the regime for Guantanamo Bay detainees in terms of the rule of law provide sufficient evidence that people believe that the procedural elements of the rule of law are more important than the formal ones?

There are at least two reasons why this question should be answered in the negative. The first reason is that such a line of reasoning depends on the incidents that cause public outcry: These are extreme cases that are hotly debated, while the smaller problems of the rule of law and everyday experience with it are not discussed. The second reason is that it depends on a particular legal culture: Waldron's examples are American or common-law examples, and American legal culture is one of the most judicially oriented around the world. For instance, if one were to ask about rule-of-law problems in Bulgaria or Romania, chances are that general governmental corruption is seen as the most pressing rule-of-law problem. ${ }^{19}$ If the idea is that a general concept of the rule of law needs to take account of popular views of the rule of law, it seems rather limited to look only at the Anglo-American setting.

To overcome these limitations and gather more robust evidence on what ordinary people think of the rule of law, it is helpful to consider empirical social scientific work. More particularly, because the argument depends on what people think of the rule of law, the scholarship on legal consciousness is a promising source for support of the claim that people regard procedural rule-of-law principles as the most important. Rather than opinion polling the general population's views on rule of law, legal consciousness research focuses on the everyday significance of law and the way this shapes and is shaped by what people believe and do. ${ }^{20}$ In The Common Place of Law,

\footnotetext{
${ }^{19}$ Sabina Pavlovska-Hilaiel, 'The EU's Losing Battle Against Corruption in Bulgaria', Hague Journal on the Rule of Law 7 (2015), 199-217; Bojan Bugaric, 'The Rule of Law Derailed: Lessons from PostCommunist Countries, Hague Journal on the Rule of Law 7 (2015), 175-197.

${ }^{20}$ Patricia Ewick and Susan S. Silbey, The Common Place of Law. Stories from Everyday Life (Chicago: Chicago University Press, 1998), pp. 34-35.
} 
Ewick and Silbey developed a typology of attitudes towards the law based on interviews. Distinguishing between positions 'before the law', 'with the law' and 'against the law', they show how people's attitudes towards law differ depending largely on the situations in which they find themselves. ${ }^{21}$ Their research thus shows that different cultural attitudes to law are available: People may believe in law's autonomy and formal rules as a system that does not really concern their everyday life ('before the law'), they may see law as a game they can play in their own interest ('with the law') or they may see law as an oppressive force to be resisted ('against the law'). This research does not really support a general claim about the rule of law. Only the attributes of being 'before the law' have a relation to a rather formal idea of rule of law. Procedural fairness does not play a large role here, because people with this attitude do not see law as an opportunity for their own engagement. Neither the manipulation by the group 'with the law' nor the scepticism of being 'against the law' points to much faith in the link between law and procedural values. Of course, this does not necessarily entail that the rule-of-law value has become irrelevant or has taken on a completely different meaning. It might be that a negative attitude about the existing legal system is fuelled by disappointment about the realization of rule-oflaw values. If people come to legal institutions with the expectation of delivery of justice, and are disappointed, this could very well mean that the ideal of rule of law as procedural is what they see being thwarted. This strand of legal consciousness research thus gives insight in the problematic relation between awareness of law and the perception of law as oriented towards the rule of law. However, it is not very informative on possible values associated with the rule of law in popular consciousness.

A more open approach, based on an idea of living law, is more promising in this respect but also directly shows the variation of rule of law cultures. Using Ehrlich's idea of living law, Hertogh researches what he calls 'the social definition of the rule of law'. ${ }^{22}$ In the context of rule-of-law promotion, Hertogh criticizes the measuring of compliance with the rule of law as defined in Western legal thought. He advocates using a working model of the rule of law,

\footnotetext{
${ }^{21}$ Ewick and Silbey, The Common Place of Law, p. 51.

${ }^{22}$ Marc Hertogh, 'Your rule of law is not mine: rethinking empirical approaches to EU rule of law promotion', Asia Europe Journal 14 (2016), 43-59. (DOI 10.1007/s10308-015-0434-x)
} 
broadly sketched as 'the most desirable relation between law and the state $^{, 23}$ (or law and official authority more broadly), to look for ruleof-law values without predetermining their meaning theoretically. In the case study he discusses, a study of life in a Burmese refugee camp, these values turn out to be harmony and order rather than rule-based reasoning or procedural argument. Hertogh's research reinforces points made earlier by socio-legal scholars such as Selznick, Krygier and Cotterrell that the rule of law only gains specific meaning in a particular context and legal culture and that there is huge variation in the understandings of the rule of law. ${ }^{24}$

It may well be that the court-centred procedural ideal of the rule of law is indeed particular to the Anglo-American tradition. For instance, in the American research of Tyler, procedural fairness turns out to be a central value that people use to evaluate their encounters with the law. ${ }^{25}$ Tyler contrasts procedural fairness with the outcomes: People care about the way they are treated and the opportunities they have to voice their point of view rather than just paying attention to the result of the procedure. Although this supports Waldron's point, the research is limited from a rule-of-law point of view because the contrast between procedures and outcomes was the focus in the research set-up, and other rule of law aspects, such as the clarity of rules or non-discrimination, were not included in the research. ${ }^{26}$ Moreover, contrasting this work with that of Hertogh, it may well be that in a legal culture that is court-centred, values associated with courts become prominent in people's ideas about rule of law. There is no good way of disentangling the long-term existence of particular institutions from the consciousness of related rule-of-law values.

Therefore, a crucial insight from this discussion of socio-legal studies is that rule-of-law scholars should place their own accounts in a historical and cultural tradition. Then, even the commonalities between the common law rule of law and the civil law Rechtsstaat

\footnotetext{
${ }^{23}$ Hertogh, 'Your rule of law is not mine', p. 53.

${ }^{24}$ Philip Selznick, 'Legal Cultures and the Rule of Law', In M. Krygier and A. Czarnota (eds.) The Rule of Law after Communism (Dartmouth: Ashgate 1999), pp. 21-38; Martin Krygier, 'Four Puzzles about the Rule of Law: Why, What, Where? And Who Cares?', p. 98-99; Roger Cotterrell, 'Law in Culture', Ratio Juris 17 (2004), 1-14 on law and culture more generally.

25 Tom Tyler, 'Procedural Justice, Legitimacy, and the Effective Rule of Law', Crime and Justice 30 (2003), 283-356.

${ }^{26}$ The research is focused on encounters with the police and courts, Tyler, 'Procedural Justice', p. 285.
} 
show up as superficial similarities having very different backgrounds. ${ }^{27}$ Going back to the English Magna Carta or the French Revolution shows a difference in emphasis at the very least. ${ }^{28}$ The English rule of law emphasizes ordinary law administered by courts, as in the classic 19th century formulation of the rule of law by Dicey. ${ }^{29}$ The German 19th century tradition of the Rechtsstaat was linked to struggles with the authoritarian state and explains the emphasis on formal legality, the idea that all state action must have a basis in legislation. The French idea of l'Etat de droit, emerging after the revolution, also needed to deal with the power of the legislature, but the French debate also referred to the Declaration of the Rights of Man, which might explain why in the French legal tradition both a strong focus on the legislature and on equal rights can be found. This is not so much a matter of understanding the historical shape of the rule of law itself, but of understanding the legal traditions that give us the resources to think about the rule of law in certain ways, and not in others. The historical dimension may create awareness of the links between political developments, ideas about law, and institutional structures, and the way these historical configurations influence rule-of-law thought. Referring to popular understandings of the rule of law, but also to empirical research about those understandings is a historically situated argumentative step.

\section{BUILDING ON LEGAL DOCTRINAL SCHOLARSHIP}

In Section II, I argued that both Raz and Waldron make use of claims about legal institutions, in particular courts and court procedures, with little argument on how the court-related and procedural elements follow from the idea of the rule of law. In this section, I will examine what legal doctrinal scholarship can add to the support of that claim. In addition, I argue that legal doctrinal research also points out new directions for rule-of-law theory, particularly through its attention for the interplay between different legal orders. Before going into the specific arguments, however, it is

\footnotetext{
${ }^{27}$ Martin Loughlin, Foundations of Public Law (Oxford: Oxford University Press, 2010), p. 313.

28 Tamanaha, On the Rule of Law, p. 26 and p. 125.

${ }^{29}$ Dicey gives as the first meaning of the rule of law: 'no man is punishable (...) except for a distinct breach of law established in the ordinary legal manner before the ordinary Courts of the land', A.V. Dicey, Introduction to the Study of the Law of the Constitution, London: Macmillan 1902, pp. 183-184. Compare Martin Loughlin, Foundations of Public Law, p. 316.
} 
necessary to give a brief account of my understanding of legal doctrinal scholarship, since the concept is used in different ways.

Legal doctrinal scholarship can be broadly defined as the systematic study of legal norms in the various sources of law that form the basis of particular legal systems. ${ }^{30}$ Most legal doctrinal work is therefore the study of (a part of) a particular legal order, of English, French, European Union or international law. In the account I give here, I generalize over common law and civil law traditions. ${ }^{31}$ Legal doctrinal scholarship is the study of positive law, but in that study it takes on board the academic writing about positive law too (and in that sense is self-referential). In many legal systems, the distinction between primary sources (legislation, treaties, court cases) and doctrinal writings is not clear-cut. Doctrine serves as an important supplementary source, as most explicitly indicated in article 38 of the Statute of the International Court of Justice: 'The Court (...) shall apply (...) d. subject to the provisions of Article 59, judicial decisions and the teachings of the most highly qualified publicists of the various nations, as subsidiary means for the determination of rules of law'. The mutual influence and intertwinement of doctrinal writing and primary sources of positive law shows in the way legal doctrinal scholarship engages with practical concerns and the current state of positive law. One way to describe it is as commentary on what legislatures and courts do. ${ }^{32}$ Important characteristics of doctrinal work are its attention to detail, the use of comparative methods and working towards systematization to achieve coherence of the legal order. Although doctrinal scholarship closely follows developments in positive law and legal practice, it adds an interpretive understanding, making sense of particular instances in comparison to others and in relation to a larger whole.

Methodologically, doctrinal scholarship is a combination of describing, interpreting, and arguing about legal norms and institu-

\footnotetext{
${ }^{30}$ Compare Jan Smits, 'What is Legal Doctrine? On the Aims and Methods of Legal-Dogmatic Research', in: R.van Gestel, H.-W. Micklitz \& E. L. Rubin (eds.), Rethinking Legal Scholarship: A Transatlantic Dialogue, (New York: Cambridge University Press, 2017), pp. 207-228, at p. 210: '[R]esearch that aims to give a systematic exposition of the principles, rules and concepts governing a particular legal field or institution and analyses the relationship between these principles, rules and concepts with a view to solving unclarities and gaps in the existing law'.

${ }^{31}$ The argument is general but not universal: I consider the broad traditions of Western legal systems but do not claim this is a necessary feature of doctrinal scholarship across the globe.

${ }^{32}$ W. T. Murphy and Simon Roberts, 'Introduction', Modern Law Review 50 (1987), 677-687; Richard Posner, 'The Present Situation in Legal Scholarship', Yale Law Journal 90 (1980), 1113-1130, at p. 1113 argues it is focused on court decisions.
} 
tions. The interpretive stance of legal scholars, establishing the meaning of given legal materials in the context of a legal field or system, is often seen as the key characteristic of legal methodology. ${ }^{33}$ Description and comparison are often combined with interpretation and argument regarding norms and values. In doctrinal legal scholarship, normativity is part of the subject matter to be described accurately and systematically, but it is also the core of the arguments doctrinal scholars make. ${ }^{34}$ Doctrinal scholarship cannot do without detailed knowledge of positive law, but that knowledge is not only used for description but also as a source of normative argument. ${ }^{35}$ Doctrinal scholarship differs from philosophical work in this grounding of argument in the context of existing law and in its internal perspective: It contributes to the development of legal practice. $^{36}$

Using these characteristics, I propose to see the particular contribution of legal doctrinal scholarship as the descriptive and normative study of the interplay between norms of positive law, such as legal principles, statutory rules and legal cases, and their institutional context. By this I mean that a particular court decision, a specific legal regulation or statute, is studied in detail but in the light of the broader context of the area of law in which it can be classified and of the legal institutions to which it is related. A recurring type of question is how a new decision or statutory rule affects the larger framework of norms and institutions: Does it fit the larger system, will it change the interpretation of legal concepts or principles and does it shift the balance between court and legislature? As Singer argues, lawyers have a special sense of the complexity of law, in

\footnotetext{
${ }^{33}$ Mark Van Hoecke, 'Legal Doctrine: Which Method(s) for What Kind of Discipline?', in: Mark Van Hoecke (ed.) Methodologies of Legal Research: Which Kind of Method for What Kind of Discipline?, (Oxford: Hart, 2011) pp. 1-18.

${ }^{34}$ Jan M. Smits, 'Law and Interdisciplinarity: On the Inevitable Normativity of Legal Studies', Critical Analysis of Law $1 / 1$ (2014), 75-86.

${ }^{35}$ Sanne Taekema, 'Relative Autonomy. A Characterization of the Discipline of Law', in Bart van Klink and Sanne Taekema (eds.), Law and Method. Interdisciplinary Approaches to Legal Research, (Tübingen: Mohr Siebeck 2011), p. 33-52, at 49.

${ }^{36}$ Compare Cotterrell's idea of jurisprudence: 'The essential point is that, however wide these jurisprudential inquiries become, they start from and must relate back to conditions of legal practice and experience in their particular time and place'. Roger Cotterrell, Sociological Jurisprudence: Juristic Thought and Social Inquiry, (Abingdon: Routledge 2018), p. 56.
} 
particular of the difficulty of applying principles in concrete actual cases. $^{37}$

With this account of doctrinal legal scholarship, we can return to the issue of the rule of law: How does doctrinal work on the rule of law relate to the arguments of Raz and Waldron? In the institutional context of particular legal systems, the importance of courts for the rule of law and the principles regarding courts that Raz includes, are easily argued. The independence of courts, procedural safeguards such as an open and fair hearing, equality of arms in the courtroom, and access to justice are all elements of legal systems that are highlighted in doctrinal legal scholarship. Doctrinal scholars not only discuss these issues positively, showing that they are a central part of mature legal systems, but they also do so critically, criticizing legal systems for not providing sufficient safeguards or endangering procedural rights. Thus, the principles Raz mentions can be supported by appealing to legal doctrinal arguments.

For example, the independence of courts from other branches of state power is not only well established as a principle of constitutional law, but also elaborated in doctrinal work. Constitutional legal scholarship also has much to say about the requirements for independence and about the institutional relationship between courts and legislatures, on which legal and political philosophy are usually silent. ${ }^{38}$ As Möllers claims, 'What constitutional scholarship lacks in theoretical insight, it compensates by focusing on actual institutional practices, ${ }^{39}$ From a doctrinal point of view, the independence of courts supports the rule of law because it ensures that the power to determine the meaning of legal rules is shared by institutions that are organized as separate bodies. On this view, it is not so much separation of powers, but a sharing of powers by separate institutions that promotes the value of rule of law. The fact that courts, the judges of which are not directly accountable to other government

${ }^{37}$ Joseph William Singer, 'Normative Methods for Lawyers', UCLA Law Review 56 (2009), pp. 899982, at 938-39.

${ }^{38}$ There are exceptions, of course. A combination between legal constitutional scholarship and political and legal philosophy is provided by Christoph Möllers, The Three Branches: A Comparative Model of Separation of Powers (Oxford: Oxford University Press, 2013). From a legal theory perspective, Kyritsis introduces separation-of-powers doctrine into an interpretivist rule-of-law account, Dimitrios Kyritsis, 'A New Interpretivist Conception of the Rule of Law', Problema 10 (2016), 91-109. Palombella frames the idea of the rule of law as an institutional ideal, Gianluigi Palombella, 'The Rule of Law as an Institutional Ideal', Comparative Sociology 9 (2010), 4-39, https://doi.org/10.1163/ $156913210 X 12535202814315$.

${ }^{39}$ Möllers, Three Branches, p. 2. 
institutions, need to interpret and apply the rules produced by lawmakers creates an interplay between legislatures and courts that curbs the power of each. This argument entails that the independence of courts has a slightly different relationship to the overarching rule-of-law ideal than suggested by Raz, who sees courts as necessary to provide practical guidance to legal subjects. Court interpretation may be important for that reason, but it is more important to prevent legislatures from creating arbitrary rules. This may still fit the Razian argument, but it does so indirectly: It is the complex of legislative and judicial work that prevents arbitrary rules, which may then contribute to law's guidance function.

In this discussion of the principle of court independence, it is already apparent that doctrinal scholarship not only provides supportive arguments but also reinterprets the idea of the rule of law from the perspective of the institutional context. This point can be generalized and extended: Legal doctrinal research also points to the variation and developments in positive law when it comes to upholding these principles. A particular strength of doctrinal research is that it reflects on the changes that take place in the legal systems it studies. One of the largest changes in positive law over the last decades has been the intertwinement of international law and national law, especially in the European context. ${ }^{40}$ Both the European Union and the European Convention of Human Rights have been recognized in legal doctrine as changing the character of the national legal systems falling within their reach. ${ }^{41}$ These changes also affect the rule of law: There are new institutions promoting (their version of) the rule-of-law ideal, which in turn gives rise to tensions that ruleof-law research needs to make sense of.

These changes to the rule of law can be found both at the level of particular principles and at the overarching level of the rule-of-law ideal itself. A good example of the former in the context of the Razian rule-of-law principles is the case law of the European Court of Human Rights (ECtHR) on the right to a fair trial. Although the various European legal systems all encompass notions of fair trial,

\footnotetext{
${ }^{40}$ Although these developments are most advanced in Europe, there are many regional organizations with similar cooperative goals, such as the African Union or the Association of South East Asian Nations. In the following I focus on the European context.

${ }^{41}$ E.g. Joe Weiler, 'The Transformation of Europe', Yale Law Journal 100 (1991), 2403-2483; Helen Keller and Alec Stone Sweet, A Europe of Rights. Assessing the Impact of the ECHR on National Legal Systems (Oxford: Oxford University Press, 2008).
} 
traditionally there was great variation, for instance between adversarial and inquisitorial systems of criminal justice. ${ }^{42}$ Under the influence of the ECtHR's interpretation of article 6 of the European Convention, adversarial elements were introduced in systems that were traditionally inquisitorial. ${ }^{43}$ This does not mean that the differences between the inquisitorial and adversarial traditions have completely disappeared, but it does mean that there are developments that make it more difficult to apply the traditional labels. ${ }^{44}$ Within European legal systems, at least, the meaning of principles of procedural justice cannot be taken for granted. Rather than simply stating that they include 'open and fair hearing, absence of bias, and the like, ${ }^{45}$ research on internationalization and national divergences of these principles shows the variation in their interpretation and the difficulties in some legal orders to adjust their procedures to the international standard, whether it is because of entrenched ideas in legal culture, practical problems or national politics.

The more fundamental point regarding internationalization and regionalization of law is the challenge to rule-of-law conceptualization: Is it still correct to think of rule of law as an ideal for and within national legal systems only? Within rule-of-law theory, there is some discussion of the rule of law at the international level. For instance, Waldron pays attention to the question whether there is a recognizable rule of international law. In 'The Rule of International Law' Waldron asks: '(...) what the rule of law demands of lawyers in the international arena'. ${ }^{46} \mathrm{He}$ discusses the question as parallel to a municipal rule-of-law question, with the state in the place internationally of individuals nationally. Although Waldron distinguishes the state from individuals in terms of their obligations, methodologically it is an exercise of comparing and contrasting two models. With the legal doctrinal discussions on the interrelations between

\footnotetext{
${ }^{42}$ Stewart Field, 'Fair Trials and Procedural Tradition in Europe', Oxford Journal of Legal Studies 29/2 (2009), 365-387.

${ }^{43}$ Although the argument is made that the Court's interpretation is not clearly adversarial but more broadly participatory: John D. Jackson, 'The Effect of Human Rights on Criminal Evidentiary Processes: Towards Convergence, Divergence or Realignment', Modern Law Review 68 (2005), 737-764.

${ }^{44}$ Compare Field, 'Fair Trials and Procedural Tradition in Europe', p. 382.

${ }^{45}$ Raz, Authority of Law, p. 217.

${ }^{46}$ Jeremy Waldron, 'The Rule of International Law', Harvard Journal of Law and Policy 30 (2006), 15 30. Joseph Raz recently also made an argument that international law affects the position of state law, see Joseph Raz, 'Why the State?', in N. Roughan and A. Halpin (eds.) In Pursuit of Pluralist Jurisprudence (Cambridge: Cambridge University Press 2017), pp. 136-162.
} 
international law and national law in mind, his question does not go far enough. It is not a matter of the need to transfer the rule of law to the international legal realm, so that we have two versions: a national and an international rule of law. It is a matter of conceptualizing how the fact that international norms and institutions codetermine what the law is at the national level affects the ideal of the rule of law. One of the questions asked repeatedly in connection to the United Nations and the European Union is whether such international organizations have a responsibility for promoting the rule of law in their member states. Thus, one could ask the question whether a transnational rule of law needs to include a principle of oversight of national orders by international institutions. ${ }^{47}$ For some doctrinal scholars, that would be a logical next step; for example, Bingham includes a principle linking national and international law in his account of the rule of law. His eighth principle reads, 'The rule of law requires compliance by the state with its obligations in international law as in national law', which he primarily applies to states' international obligations under international law but he also points to human rights as an area of law that is protected internationally, but co-developed at the national level. ${ }^{48}$ Reflecting on such doctrinal statements, a conceptual question may be raised whether the rule-of-law ideal can be reconstructed to cover both national and international institutions and to address the way they ought to relate to each other. Thus, the direction of legal doctrinal research generates a conceptual challenge to reconstruct the meaning of the rule of law to respond to these legal developments.

\section{TRIANGULATION: COMPLEMENTARY METHODOLOGIES AND DISCIPLINES}

Each of the three disciplines has a distinct perspective with specific substantive research interests and its own methodological approach. I have so far been optimistic about the synergies between these three perspectives, but one could be more sceptical: If the questions asked

\footnotetext{
${ }^{47}$ This discussion is primarily conducted in two arenas, the debate on rule-of-law promotion and on European Union rule-of-law oversight. See for the former, e.g., Stephen Humphreys, The Theatre of the Rule of Law: Transnational Legal Intervention in Theory and Practice, Cambridge: Cambridge University Press 2010; for the latter, Carlos Closa and Dimitry Kochenov (eds.) Reinforcing Rule of Law Oversight in the European Union, (Cambridge: Cambridge University Press 2016).

${ }^{48}$ Tom Bingham, The Rule of Law (London: Allen Lane 2010), pp. 110-119.
} 
and the answers given are articulated in a different language, is it worthwhile to try to combine them?

My argument so far assumed that the hints at empirical and doctrinal knowledge from within legal philosophy are a first step toward collaboration between the disciplines to find support for these kinds of arguments, but it is possible to argue in the other direction. Maybe it is advisable to steer clear of empirical and doctrinal arguments altogether and limit the legal philosophical argument to conceptual and/ or value-based reasoning only. Various legal philosophers characterize and justify their own approaches in contrast to sociology of law, arguing against the need to engage with socio-legal work. ${ }^{49} \mathrm{Raz}$, for example, sees legal philosophy as engaging with universal and necessary characteristics of law, while sociology of law describes particulars of various legal systems. As Raz states, sociology of law 'provides a wealth of information' on contingent features of existing legal systems, while legal philosophy needs to focus on 'those few features that all legal systems necessarily possess. ${ }^{50}$ However, this division of labour is questionable: How do we know what the necessary features are without knowledge of the contingent features? As I have argued in Section II, features that are presented as necessary for the rule of law, such as independent courts, may turn out to be contingent upon further examination. As Giudice argues, there is good reason for legal philosophers to expand their research beyond the necessary and universal characteristics of law, which he sees as a need to move from conceptual analysis to 'constructive conceptual explanation' in order to address the observed pluralism of existing conceptions of law. ${ }^{51}$

As must be clear from the earlier discussion, I agree with Giudice that we need to move beyond legal philosophy as a self-contained project. An important reason for this point of view is that even clearly conceptual and normative arguments are embedded in traditions of thought that have been influenced by historical events and

\footnotetext{
${ }^{49}$ Hans Kelsen is perhaps the most famous defender of the separation of the projects of the science of law and sociology, following from his strict separation of 'is' and 'ought'. See Ota Weinberger, 'Introduction: Hans Kelsen as Philosopher', in Hans Kelsen, Essays in Legal and Moral Philosophy (Dordrecht/Boston: Reidel 1973), p. XI.

${ }^{50}$ Raz, Authority of Law, pp. 104-105.

${ }^{51}$ Giudice, Understanding the Nature of Law, p. 38. Compare also Langlinais and Leiter, 'The Methodology of Legal Philosophy'.
} 
practices in society and law. Ignoring the interactions between concepts and values, on the one hand, and social and legal practices, on the other, impoverishes normative and conceptual work. An important question, therefore, is how the recognition of the pluralism of traditions and conceptions of rule of law, as of law more generally, affects the project of legal philosophy: How should the challenge of pluralism be taken up? One way of doing this is by limiting the amount or scope of universal characteristics. Raz, for instance, clearly sees municipal legal systems as the central category to be analysed. ${ }^{52}$ There is no need for a conceptual analysis that includes non-state or international law. A second and third possibility are based on an explicit acknowledgement of the diversity of forms of law. Giudice's solution is to look for general contingent features rather than universal and necessary features, thus admitting that a conceptual construction may leave some instances of law unexplained. ${ }^{53}$ By contrast, the third possibility is to pluralize the concept of law itself, claiming that there is a set of plural legal forms. Lon Fuller's work on enacted versus interactional law is a good example. ${ }^{54}$ This can be construed as a claim of necessary pluralism: Both forms of law need to be part of the concept in order to grasp the notion of law. The latter two approaches are both productive ways of engaging with pluralism. Since various responses to plurality are possible, I do not think it provides a knockdown argument against the possibility of universal characteristics, although these may be so few that their explanatory power is very limited.

Continuing then with the exploration of the combination of perspectives, an idea from social science methodology may serve as a starting point. In social sciences, an often-used methodology is that of triangulation: using different methods to answer the same question in order to corroborate or complement results. ${ }^{55}$ The assumption is that finding the same results with different methodological

\footnotetext{
${ }^{52}$ Raz, Authority of Law, p. 105.

${ }^{53}$ Giudice, Understanding the Nature of Law, p. $67 \mathrm{ff}$.

${ }^{54}$ Lon L. Fuller, 'Human Interaction and the Law', in Kenneth I. Winston (ed.), The Principles of Social Order. Selected essays of Lon L. Fuller (Durham: Duke University Press, 1981), pp. 211-46.

55 Another often-used term for this is mixed-methods research. There are debates on what the value of such a methodological approach is and on the purposes of using it (corroboration or complementarity). Usually, the focus is on the combination of quantitative and qualitative empirical methods. See Abbas Tashakkori and Charles Teddlie (eds.), Sage Handbook of Mixed Methods in Social and Behavioral Research $2^{\text {nd }} \mathrm{ed}$. (Thousand Oaks: Sage 2010); Norman K. Denzin, 'Triangulation 2.0', Journal of Mixed Methods Research 6 (2) (2012), 80-88.
} 
tools strengthens the support for those results, and makes the conclusions better warranted. Thus, if a researcher interested in the role of cultural differences in the courtroom finds that his interviews with judges show that they regard defendants from cultural minorities differently, and that his courtroom observations point out differences in the interactions between judges and defendants from minority groups compared to defendants from the dominant culture, and that analysis of verdicts shows differences in justification, such triangulation may be said to strengthen the conclusion that judges are sensitive to cultural differences between defendants. ${ }^{56}$ In this example, the methods discussed are all forms of qualitative research, and they can all be used to answer the same question. Such corroboration is more problematic when the combination is between methods that are very different in orientation. Triangulating quantitative and qualitative research methods is less likely to lead to comparable results, not least because these methods are suited to answer different types of questions. Interviews, for example, suit research into perceptions and reasons people have, while experiments are a proper technique to find correlations and possible causes. This does not necessarily entail that triangulation with such diverse methodological tools is not possible; rather it shows that methodological triangulation does not always serve the purpose of corroborating results, but may also serve to complement different insights. If we acknowledge that methods have limited suitability, i.e., they can only be used to answer particular types of questions, then it makes sense to combine methods to overcome these limitations. Thus, in the example of cultural differences in the (criminal) courtroom, we may want to include differences in sentencing outcomes, an aspect that is best researched by analysing a large data set.

Once the complementary form of triangulation is accepted as a valid strategy, interdisciplinary triangulation can be seen as a natural next step. ${ }^{57}$ Here too, the methods complement each other and may serve to uncover aspects that the other discipline cannot see or can only partly understand. Making the argument for complementarity

\footnotetext{
56 This is a fictitious example. For a quantitative study on such matters, see David L. Faigman et.al. 'Implicit Bias in the Courtroom', UCLA Law Review 59 (2012), 1124-1186.

${ }^{57}$ An argument why this is nonetheless problematic may use Kuhn's idea of paradigms to argue that there are incompatible presuppositions in different disciplines, Thomas Kuhn, The Structure of Scientific Revolutions, (Chicago: University of Chicago Press 1970); see also Ubaldus De Vries, 'Kuhn and Legal Research: A Reflexive Paradigmatic View of Legal Research', Law and Method 3/1 (2013), 7-25.
} 
between legal philosophy, empirical socio-legal science and legal doctrinal scholarship requires a sense of the distinctive contributions of each and possible connections between them.

Legal philosophy is distinctive in its use of conceptual arguments about core ideas in law, many of which are normative, such as rules or rights, or have a normative aspect, such as authority or courts. The focus on normative ideas also creates a need for normative arguments to support the substance of these ideas. Characteristic of the methods of legal philosophy is the construction of theoretical arguments based on various conceptual elements leading to a coherent account of basic ideas about law. In practice, the methods are primarily discursive: examining arguments and counter-arguments, building on existing theoretical work and aiming to improve on that work by presenting an alternative or modified account. Abstract theoretical arguments are confronted with concrete elements in various forms: common sense judgments or everyday language use, hypothetical or real examples. ${ }^{58}$ The aims of legal philosophy may differ: ${ }^{59}$ They may be descriptive, aiming to make sense of the meaning and use of legal (normative) concepts, or normative, aiming to justify the use of certain normative principles or values or to argue for the superiority of a particular conception. For example, Paul Gowder's book on the rule of law is in large part a normative argument why the book's central concept of the rule of law should be interpreted as requiring equality, but it also makes use of conceptual arguments about the various elements of the rule of law ordinarily included in the rule of law. ${ }^{60}$ His conceptual and normative arguments are not neatly separated but combined in a larger philosophical argumentation. This is different in analytical philosophy, which focuses on conceptual analysis, but I do not take analytical legal philosophy to stand for legal philosophy in general. ${ }^{61}$

\footnotetext{
${ }^{58}$ In this respect, the methods of legal philosophy resemble methods of moral philosophy, particularly that of reflective equilibrium, see Norman Daniels, Justice and Justification: Reflective Equilibrium in Theory and Practice (Cambridge: Cambridge University Press 1996).

59 This links to the debate on the methodology of legal philosophy, on the question whether to approach the normativity of law in a descriptive or normative manner, see Sean Coyle and George Pavlakos (eds.), Jurisprudence or Legal Science? (Oxford: Hart 2005).

${ }^{60}$ Paul Gowder, The Rule of law in the Real World, (Cambridge: Cambridge University Press 2016), Chapters 1 and 2. More on his method below.

${ }^{61}$ For a careful and mildly critical explanation of the methodology of analytical jurisprudence, see Michael Giudice, Understanding the Nature of Law. A Case for Constructive Conceptual Explanation (Cheltenham: Edward Elgar, 2015).
} 
Moreover, as we have seen in relation to Raz, when it comes to discussions of the rule of law, philosophers who do analytical work often engage in normative argument as well. Thus, in philosophical accounts of the rule of law, the combination of conceptual and normative argument, as also shown by Gowder, is quite common. Starting from the assumption that the rule of law is a political ideal, arguing the value of the rule of law is an important task for legal philosophy. Although I have not stressed this in the previous discussions, Waldron uses arguments about the moral value of human agency and respect for dignity to underpin his account, while also providing conceptual arguments for his procedural rule of law. ${ }^{62}$

By contrast, empirical social science focuses on providing factual evidence to understand what people do and believe. The centrality of data is characteristic: gathering and analysing facts in various ways, with an emphasis on finding information. In empirical research, the rule of law as a concept can be measured (do actual practices conform to it?) or compared to what people believe and do (as the example of Hertogh's research showed). Empirical research is therefore not so much interested in justifying these values as it is in understanding or explaining why they are upheld or not. The values of the rule of law are taken as a measurement criterion or transformed into something that is part of people's actual beliefs and practices. In this article, I focus primarily on the latter, the research on cultural understandings of the rule of law, while there is also a good deal of research on the rule of law from a more quantitative angle. This would lead to including other disciplines such as economics and political science as the empirical perspective. ${ }^{63}$ The reason for my focus on this form of socio-legal studies lies in the arguments that are needed to complement the views of Waldron and Raz: Their argumentation leads in this direction.

\footnotetext{
${ }^{62}$ Elsewhere, I have argued that his normative arguments on agency are the strongest part of his rule-of-law theory, see Sanne Taekema, 'The procedural rule of law: Examining Waldron's argument on dignity and agency', Annual Review of Law and Ethics, Volume 21, edited by B.S. Byrd, J. Hruschka, and J.C. Joerden (Berlin: Dunckler and Humblot 2013), pp. 133-146.

${ }^{63}$ An example is Nadia E. Nedzel, 'The Relationship between the International Rule of Law, Spontaneous Order and Economic Development', ICL Journal 28/2 (2018), 183-211, who uses empirical economics and legal history as complementary perspectives. More broadly on the rule of law and economic development, see, e.g., Kenneth W. Dam, The Law-Growth Nexus: The Rule of Law and Economic Development (Washington, D.C.: Brookings Institution Press 2006), and Stephan Haggard, Andrew MacIntyre and Lydia Tiede, 'The Rule of Law and Economic Development', Annual Review of Political Science 11 (2008), 205-234.
} 
The distinctiveness of legal scholarship is the most difficult to grasp, but here the focus is on the normative content of the law as an institutionalized coherent practice. Legal doctrine focuses on the meaning of legal texts in a particular institutional setting, of a legal system or particular legal regime, often in comparison to other systems or regimes, and studies these texts in that context. Because of its contextual and institutional orientation, it can provide detailed descriptions that clarify relations between norms, procedures, roles and arguments. Because of its focus on coherence, it pays specific attention to the relation between the particulars of the text or case and the larger whole of the system. ${ }^{64}$ Legal doctrinal scholarship does not question the value of the rule of law but is interested in how it works in specific legal contexts. ${ }^{65}$

Considering the similarities and differences between the three disciplines, legal philosophy and doctrinal legal scholarship seem linked more closely than either of them is to empirical socio-legal science. The difference between the first two can be characterized as focus on the general versus the particular: where legal philosophy tends towards general arguments, doctrinal scholarship focuses on the way law is applied concretely in particular contexts, and on comparison of these particular instances. There are also significant similarities, which can be summarized as a hermeneutic methodology: linking descriptive and normative aims and arguments and using interpretive and argumentative reasoning. Empirical socio-legal science, by contrast, focuses on description and explanation, staying away from normative claims, and uses a data-based empirical method.

One way to view complementarity of these three disciplinary perspectives is to advocate a division of labour in a strict order: First, legal philosophy provides a careful argument for a particular conception of the rule of law; second, legal doctrinal scholarship shows how the rule of law conception is given a particular shape and applied in legal institutions and third, empirical science uses this conception to find out whether actual rule-of-law practices deserve to be labelled 'rule of law', and whether what goes on in the rule-of-

\footnotetext{
${ }^{64}$ Neil MacCormick, Rhetoric and the Rule of Law. A Theory of Legal Reasoning (Oxford: Oxford University Press 2005), pp. 190-193.

${ }^{65}$ Comparable to how Dagan and Kreitzer describe 'law as craft': Hanoch Dagan and Roy Kreitzer, 'The Character of Legal Theory', Cornell Law Review 96 (2011), 671-691, at 677-680.
} 
law institutions has meaning in people's everyday lives. In various combinations, such work is done. ${ }^{66}$ However, more interesting combinations go beyond complementarity and critically reflect upon the other disciplines. Ideally, the criticized discipline takes on board the criticism and tries to reorient itself to incorporate it. Thus, the most demanding form of triangulation of perspectives is to allow for corrections of one's own perspective based on the criticism voiced by the others. This requires a sensitivity to each other's projects, acknowledging the value of the other perspective. It entails thinking about the way in which one's criticism may be received by the discipline under scrutiny, being careful to avoid complete dismissal and posing questions in such a way that it opens up new directions for the other discipline. This is not to say that fundamental critique is always unwarranted; there is an argument to be made, for instance, for criticizing the philosophical idea of the rule of law as biased towards liberal individualism. ${ }^{67}$

The idea of triangulating legal philosophy, empirical social science and legal doctrinal scholarship can be criticized for two types of reasons: conceptual and methodological. The conceptual objection is that my classification of the three disciplines is wrong: Why distinguish these three? Other theorists advance an interdisciplinary methodology for legal theorists who draw the lines in different places. An attempt to do this for rule-of-law research is Paul Gowder's book, The Rule of Law in the Real World, in which he makes a combination of conceptual/normative legal philosophy with empirical work. He puts law and philosophy in the same camp, as the providers of 'normative/conceptual tools'. ${ }^{68}$ However, he also lists law as one of the disciplines providing knowledge of 'real-world institutions, ${ }^{69}$ which makes it seem as if the discipline of law has a double function in Gowder's account: both the source of normative principles and the provider of knowledge of real institutions. This points to the difficulty of distinguishing the normative and the

\footnotetext{
${ }^{66}$ Often, there are two steps: the conceptual and the empirical, see e.g. Jørgen Møller and SvendErik Skaaning, The Rule of Law. Definition, Measures, Pattern and Causes (Houndmills: Palgrave Macmillan, 2014).

${ }^{67}$ Makau Mutua, 'Africa and the Rule of Law', Sur. International Journal on Human Rights 23 (2016), pp. 159-173.

${ }^{68}$ Gowder, Rule of Law in the Real World, p. 4. For a substantive review, see Peter Rijpkema, 'Paul Gowder. The Rule of Law in the Real World - Book Review', Ethics 127 (2017), pp. 486-491.

${ }^{69}$ Gowder, Rule of Law in the Real World, p. 3.
} 
descriptive in the legal field. ${ }^{70}$ However, if our interest is in the justification of conceptions of the rule of law, it is important to keep track of the kind of argument advanced - conceptual, empirical, or institutional - because the support needed for such arguments differs. Another interesting argument, about the concept of law rather than the rule of law, is given by Michael Giudice, in Understanding the Nature of Law. Giudice argues for the need to combine conceptual legal philosophy with empirical social science and moral theory, leaving out legal doctrinal work. In his framework, it seems that legal doctrine does no more than provide the problems to which the combination of the other three disciplines gives answers. As will be apparent from my earlier account, I think this misses the important contribution of legal doctrinal scholarship as providing contextual arguments about the institutional side of the rule of law. ${ }^{71}$

An objection to my idea of triangulating distinct perspectives could be that it stops short of what good scholarship should do, namely to integrate perspectives. Rather than argue that there are three different perspectives that need to speak to each other, one could argue that insights from each of these perspectives need to be synthesized into a disciplinary perspective of its own. ${ }^{72}$ Dagan and Kreitzer make this argument in their defence of legal theory as a middle position between what they see as the dominant other approaches to law: law as craft, law and policy and sociohistorical analysis of law. Philosophy of law could well be added as a fourth corner to which their idea of legal theory relates: 'One manifestation of the significance of law and craft for legal theory is legal theory's tendency to be less abstract than the philosophical, economic, or other theories with which it interacts. ${ }^{73}$ What is crucial in their account is that legal theory is a 'synthesis' necessary to deal with law as a complex and multi-faceted phenomenon. ${ }^{74}$

The triangulation idea advanced here is more modest: Rather than claim that we need a synthetic discipline of legal theory, I think

\footnotetext{
${ }^{70}$ As argued in the previous section; compare Taekema, 'Relative Autonomy', pp. 35-36.

${ }^{71}$ Compare the criticism of Cotterrell of (analytical) legal philosophy, as insufficiently informed by juristic concerns, Sociological Jurisprudence, pp. 51-55.

${ }^{72}$ Such an argument is made by James Boyd White in relation to law and literature; see his 'Establishing Relations between Law and Other Forms of Thought and Language', Erasmus Law Review $1 / 3$ (2009), pp. 3-22.

${ }^{73}$ Dagan \& Kreitzer, 'The Character of Legal Theory', p. 686.

${ }^{74}$ Dagan \& Kreitzer, 'The Character of Legal Theory', p. 687.
} 
it is ambitious enough to ask of the separate disciplines working on the rule of law to take seriously the implications of the other disciplines for their own work. Thus, legal philosophers need to take on board the developments in legal doctrinal scholarship and socio-legal studies that are a reason to question certain preconceived ideas, like the notion that the state legal system is the central case to account for. ${ }^{75}$ This may be reason to investigate how a universalizing approach of the rule of law can respond to pluralism arguments. How such triangulation might work is best explained by way of an example.

\section{THE RULE OF LAW INDEX AS AN EXAMPLE}

A striking phenomenon of the last decennia has been the increased use of indicators to measure the rule of law. There are various indexes that link to rule-of-law concerns, focusing on issues such as corruption, freedoms and doing business. Of the indexes that focus particularly on rule of law, the Rule of Law Index developed by the World Justice Project (hereafter: the Index) stands out because it is built on data that are collected specifically for this purpose. ${ }^{76}$ Data gathered yearly through questionnaires are scored and combined to rank countries on their rule-of-law quality. Such an index raises a number of questions to which the perspectives of legal philosophy, socio-legal studies and doctrinal scholarship make valuable contributions. The general problem is the adequacy of the Index for capturing the concept of the rule of law. This question is one for which triangulation seems to offer a good approach. The conceptualization of rule-of-law values and principles is not only key to the set-up of such an index, but can also be used in a critical mode to assess the outcomes. In an article explaining the way the Index was designed, Botero and Ponce explicitly address the issue of turning a theoretical concept of the rule of law into variables measurable

\footnotetext{
${ }^{75}$ Although I believe these are the main disciplines, there may also be reason to draw on other disciplines such as political science and history. Although these have their own characteristics, they share the empirical orientation with socio-legal studies.

${ }^{76}$ The most recent report is World Justice Project Rule of Law Index 2017-2018, available at https://worldjusticeproject.org/our-work/publications/rule-law-index-reports/ (last accessed 4 January 2019). For a general analysis, see René Urueña, 'Indicators and the Law: a case study of the Rule of Law index’, in: Sally Engle Merry, Kevin E. Davis \& Benedict Kingsbury (eds.) The Quiet Power of Indicators: Measuring Governance, Corruption, and Rule of Law (Cambridge: Cambridge University Press 2015), pp. 75-102.
} 
through questionnaires. ${ }^{77}$ This raises questions of the precise theoretical conception that is put forward, the operationalization of its components and the context of its application. Although a full discussion of the Index in terms of a triangulation approach is not possible within the confines of this article, I can sketch the issues to which the approach contributes in relation to the theoretical rule-oflaw discussions.

Two ways of linking the Index to the idea of triangulation seem possible: a narrow and a broad way of combining the three perspectives. The narrow application of triangulation uses the Index itself as the socio-legal component, providing the empirical data. The question then is what the legal-philosophical and legal doctrinal perspectives offer as corroborations, challenges or corrections to the picture provided by the Index and its methodology. At first glance, the Index is in line with the formal and procedural rule-of-law conceptions of both Raz and Waldron, as Botero and Ponce summarize its ideas as: 'ideas, which rotate around the principles that political power must be exercised in accordance with law rather than in an arbitrary or self-interested manner, and that disputes among private individuals and between them and the Sovereign must be subject to independent adjudication' ${ }^{78}$ However, when looking more closely, it becomes clear that Botero and Ponce have a more expansive, and substantive, view of the principles necessary to achieve rule-of-law quality. Of the nine factors they distinguish, the fourth factor is fundamental rights, and in some of the sub-factors, other rights-based indicators appear, such as a free press and free elections. Because this substantive component is not really supported by arguments other than an appeal to 'a common theme' and to the United Nations' definition of the rule of law, ${ }^{79}$ the legal-philosophical approach may serve as a valuable source of argument to complement the theoretical framework. Especially Waldron's normative arguments for a procedural rule of law as enhancing human dignity and agency help to join rights to formal procedure. Because court procedures are crucial to participation of individuals in legal matters, allowing them to express their own views and confirming their

\footnotetext{
77 Juan Botero and Alejandro Ponce, 'Measuring the Rule of Law', World Justice Project Working Paper Series nr 1, November 2010, available at https://ssrn.com/abstract=1966257.

${ }^{78}$ Botero and Ponce, 'Measuring the rule of law', p. 5.

${ }^{79}$ Botero and Ponce, 'Measuring the rule of law', p. 5.
} 
status as human agents, they have both formal and substantive value. However, this does not generate an argument for full-blown fundamental-rights protection as part of the rule of law, which would need further reasoning based on dignity and equal participation. If individuals need equal opportunities to participate in procedures in order to recognize their dignity, they need the freedom and capacities to do so. Without meaningful access to justice or knowledge about procedural rights, a procedural rule of law will not be realized. Although this widens the scope of the rule of law beyond Raz's elements, Waldron's theory does restrict the scope of rights to those with procedural relevance. With regard to a second issue - the operationalization of the factors - a noticeable feature of the Index is that it is set up to be outcome-oriented, looking at how the rule of law is achieved in practice. ${ }^{80}$ Thus, the questions asked concern experiences with government procedures and the justice system rather than the existence of such institutional elements. However, from a legal-doctrinal perspective this outcome-orientation seems somewhat overstated. Although some questions are about the outcomes of legal procedures, many of the questions concern the experience with the institutions themselves: e.g., awareness of procedures, possibilities to participate and experiences of impartial treatment or corruption. From a doctrinal perspective, these are questions about the functioning of the institutions and procedures that involve the process rather than simply the outcomes. Although the focus shifts from a focus on outcomes to a more even attention to institutions and the way they function, doctrinal scholarship thus actually supports the content of the Index. In such a narrow application of triangulation, I tentatively conclude that it is possible to achieve a more coherent and better-supported account of the Index project than the one provided by the makers of the Index by themselves: restricting its meaning to a substantively coloured procedural rule of law and acknowledging the importance of legal institutions in this.

While a narrow form of triangulation is mainly useful to fill gaps in the argumentation for the Index, a broader form of triangulation is potentially more critical. To construct it, I return to the points made

\footnotetext{
${ }^{80}$ Botero and Ponce, 'Measuring the rule of law', p. 16: 'The second fact is that, for the most part, our focus is on rule of law outcomes; as opposed to the institutional means, or inputs-including the legal and regulatory frameworks - to attain them'.
} 
about pluralism earlier, which may be elaborated to apply to the Index. Such a broader form of triangulation does not take the framework of the Index for granted, but also questions underlying aims and assumptions of such an assessment of the rule of law in the world. The most important methodological change from a narrow form of triangulation is to make use of other socio-legal research than the empirical data of the Index, most importantly including theoretical implications of legal sociology and anthropology. And by asking what rule-of-law aspects are not included, doctrinal scholarship may be used for criticism by applying its insights on internationalization of rule of law. Finally, the discussion in legal philosophy about the normative core of the rule of law can be used to challenge the choice of the factors of the Index and the aggregation of the scores.

This combined use of the three perspectives may be labelled a multi-faceted legal pluralism challenge: pluralism of legal orders, pluralism of legal cultures and contexts and pluralism of rule-of-law values. I do not mean to suggest that a pluralism challenge is an inevitable direction for broad triangulation - Gowder, for instance, criticizes the Index for being multidimensional rather than one-dimensional $^{81}$ - but it is a challenge that is fuelled by important insights from all three perspectives.

The pluralism of legal orders - in the sense of the interactions between international and national law - and its importance for the rule of law is a point made repeatedly by doctrinal scholars, as shown above in Section IV. ${ }^{82}$ In the Index, there is no reference to the international dimension of the rule of law (other than the use of the UN definition). A question worth asking is whether a country conforms to international norms, particularly, when it comes to rights protection, in the form of human rights treaties. From a doctrinal perspective, the internationalization of the rule of law cannot be ignored when fundamental rights are concerned: There is clear influence of international developments in national legal practices and national courts contribute to the development of these rights

\footnotetext{
${ }^{81}$ Gowder, Rule of Law in the Real World, pp. 176-181.

${ }^{82}$ E.g. André Nollkaemper, National Courts and the International Rule of Law (Oxford: Oxford University Press 2012); Tom Bingham, The Rule of Law, pp. 116-119.
} 
transnationally. ${ }^{83}$ Socio-legal studies bring forward the importance of the pluralism of legal cultures, which also has implications for the reach of the rule of law and the ways to protect it. ${ }^{84}$ The way in which the Index touches upon legal-cultural pluralism is interesting. It embraces pluralism in the ninth factor, informal justice, where it is acknowledged that the rule of law may be enhanced by effective dispute settlement by non-state actors, in traditional, religious or community-based forms. Although the Index thus incorporates the insight that access to justice may be provided in ways other than through formal courts, in the final aggregate score of the Index this factor is not counted, because the Index compilers say the mechanisms are too varied and measuring their effectiveness is too complex. ${ }^{85}$ This choice is significant: Not only do the limitations of the Index become clear - its methodology cannot cope with an aspect that is seen as necessary theoretically - it also points to a pluralism of underlying values, which also appears in a legal-philosophical perspective. If we admit that a full picture of rule-of-law realization needs to include non-state orders, the Index approach needs to be combined with other types of research, particularly the ethnographic, contextual method of legal anthropology. Thus, the sociolegal pluralism point also challenges the quantitative approach of the Index. From a different angle, the legal philosophical perspective may also do this: by developing the point of rule of law value pluralism.

A crucial debate in legal philosophy about the rule of law concerns the relationship between the ideal of the rule of law and other values and purposes. Both Raz and Waldron distinguish rule of law from these, but acknowledge the need to justify the rule of law in terms of further purposes, such as serving freedom through guidance (Raz) or protecting human dignity through procedural standing (Waldron). Both Raz and Waldron acknowledge that the rule of law may be justified by reference to different values. As discussed in Section II, Waldron even argues that the different strands of the ruleof-law ideal are in tension with each other: Whereas the formal rule-

\footnotetext{
${ }^{83}$ André Nollkaemper, 'The Internationalized Rule of Law', Hague Journal on the Rule of Law 1 (2009), 74-78.

${ }^{84}$ Compare Martin Krygier, 'Legal Pluralism and the Rule of Law', in Roughan and Halpin (eds), In Pursuit of Pluralist Jurisprudence, pp. 293-325.

${ }^{85}$ Botero and Ponce, 'Measuring the rule of law', p. 15-16.
} 
of-law aspects demand predictability to provide stability, the procedural aspects lead to openness by recognizing the arguments of individual agents, in order to acknowledge their agency. If this argument of internal value pluralism is accepted, the Index needs to be questioned on a more fundamental level. What are the values that the rule-of-law conception of the Index furthers? What is the underlying justification? This question is not explicitly addressed, but looking at the various factors, one sees links between social order and freedom, open government and participation, access to justice and non-discrimination. ${ }^{86}$ Thus, the range of different values served by rule of law according to Botero and Ponce is even broader, and the set of values seen as integral to rule of law more varied, than those advanced by Raz or Waldron. This plurality leads to problems when it comes to measuring the rule of law. As Raz argues, value pluralism implies incommensurability, ${ }^{87}$ which means that aggregating the scores of different factors, protecting different values, into one number is not possible. Aggregation leads to intriguing results; for example, Singapore scores 0.80 while Canada scores 0.81 , but the factors on which they score well are very different. ${ }^{88}$ Canada also scores well on the Freedom House index of 'Freedom in the world' $(99 / 100)$ while Singapore does not make the list of free countries, only scoring $52 / 100 .^{89}$ If the rule of law is supposed to serve individual freedom, this discrepancy is problematic. The values of social order and individual freedom may not be as clearly linked as the Index suggests. I would conclude that reporting on the Rule of Law Index is more useful without aggregating scores, that it needs to be contextualized and read in combination with other sources.

Of course, this sketch of a critique of the Index on the basis of three perspectives is only a start, and it is clear that it could be done differently. ${ }^{90}$ What I hope to have shown is that the combination of three perspectives strengthens the basis for criticism and that the three perspectives can be used to reinforce and supplement each other's arguments, when looking at a specific rule of law issue. Moreover, although I have been critical of the projects of Raz and

\footnotetext{
${ }^{86}$ Botero and Ponce, 'Measuring the rule of law', p. 10, 12 and 14 respectively.

${ }^{87}$ Joseph Raz, The Morality of Freedom (Oxford: Clarendon 1986), pp. $321 \mathrm{ff}$.

${ }^{88}$ WJP Rule of Law Index report 2017-2018, pp. 6-7.

${ }^{89}$ See the most recent Freedom House report at https: / / freedomhouse.org/report/freedom-world/ freedom-world-2018 (last accessed 4 January 2019).

${ }^{90}$ As Gowder's criticism of the Index shows.
} 
Waldron as separate legal philosophy, it turns out that their views make crucial contributions to the assessment of a concrete phenomenon such as the Index.

\section{CONCLUSION: ASKING THE RIGHT QUESTIONS}

Thus, the bottom line of interdisciplinary cooperation may not be seeing other disciplines as the source of information that can be put to use in one's own perspective, but of the other discipline providing a different framing of the issues that challenges your own discipline to change its questions. Central in this regard are the methodological limitations of each discipline: Knowing what can and cannot fruitfully be asked should be central to the conversation. Having such a dialogue, however, does entail being open to interpreting the views from the other discipline charitably, and making a genuine effort to consider in what way these can be incorporated in one's own framework. That means making sure the claims from the other discipline are well understood, but also that they can be turned into viable arguments in one's own context. ${ }^{91}$

For legal philosophers, this implies that they stand to benefit from interdisciplinary cooperation if they go beyond using common-sense knowledge of the social context of law and beyond their own partial knowledge of legal doctrines and institutions. Legal philosophy needs to be open to these forms of interdisciplinarity if it aims to be serious about all of its arguments, including the empirical and doctrinal parts of these. Moreover, legal philosophy will be more relevant for the study of law more broadly if it is willing to take a more interdisciplinary course. ${ }^{92}$ In combination with other perspectives, the philosophical study of the rule of law makes important contributions to our understanding of this central legal value.

\section{ACKNOWLEDGEMENTS}

This article has benefited from conversations with many colleagues, but I owe special thanks to Kim Lane Scheppele, Wibren van der Burg,

\footnotetext{
${ }^{91}$ One way of describing this process is James Boyd White's idea of translation between disciplines as requiring a double responsibility: staying true to the original claims, but also making the best of the receiving discipline, 'Establishing Relations between Law and Other Forms of Thought and Language'.

${ }^{92}$ Compare Cotterrell, Sociological Jurisprudence, pp. 54-55.
} 
Maksymilian del Mar and Roger Cotterrell for their comments and suggestions. I am also grateful to two anonymous reviewers for their constructive criticisms.

\section{OPEN ACCESS}

This article is licensed under a Creative Commons Attribution 4.0 International License, which permits use, sharing, adaptation, distribution and reproduction in any medium or format, as long as you give appropriate credit to the original author(s) and the source, provide a link to the Creative Commons licence, and indicate if changes were made. The images or other third party material in this article are included in the article's Creative Commons licence, unless indicated otherwise in a credit line to the material. If material is not included in the article's Creative Commons licence and your intended use is not permitted by statutory regulation or exceeds the permitted use, you will need to obtain permission directly from the copyright holder. To view a copy of this licence, visit http://creativecommons.org/licenses/by/4.0/.

Erasmus School of Law, Sanders L5-01, PO Box 17383000 DR, Rotterdam, The Netherlands

E-mail: taekema@law.eur.nl

Publisher's Note Springer Nature remains neutral with regard to jurisdictional claims in published maps and institutional affiliations. 